\title{
A PERCEPÇÃO DOSTÉCNICOS DE ENFERMAGEM EM RELAÇÃO AOS RISCOS OCUPACIONAIS EM SALAS DE VACINAS
}

Graciela Giovelli1, Sandra Maria de Mello Cardoso², Rosane Teresinha Fontana 3 , Francisco Carlos Pinto Rodrigues², Zaléia Prado de Brum²

${ }^{1}$ Estudante de Enfermagem. Universidade Regional Integrada do Alto Uruguai e das Missões. Santo Ângelo-RS-Brasil. ${ }^{2}$ Enfermeira. Mestre em Enfermagem. Professora da Universidade Regional Integrada do Alto Uruguai e das Missões. Santo Ângelo-RS-Brasil. ${ }^{3}$ Enfermeira. Doutora em Enfermagem. Professora da Universidade Regional Integrada do Alto Uruguai edas Missões. Santo Ângelo-RS-Brasil.

RESUMO: Estudo descritivo, de abordagem qualitativa, cujo objetivo foi identificar os riscos ocupacionais em salas de vacinas. Participaram da pesquisa 10 técnicos de enfermagem que atuam em cinco salas de vacina de um município no noroeste do Rio Grande do Sul. Os dados foram coletados por meio de uma entrevista semiestruturada e observação simples, e analisados por meio da análise temática no período de março a maio de 2012. Observou-se que as salas de vacinas apresentam inúmeros riscos ocupacionais e que muitos trabalhadores não os percebem, pois havia balcão com pia para lavar as mãos, mas estas tinham altura muito baixa nas cinco salas observadas, além da iluminação deficiente em todas salas. As vacinadoras entendem que os riscos ocupacionais estão relacionados somente aos acidentes de trabalho. A atenção do serviço municipal de promoção à saúde do trabalhador pode conferir valor à qualidade no trabalho destes profissionais.

DESCRITORES: Vacinas; Riscos ocupacionais; Profissionais da saúde.

\section{NURSING TECHNICIANS' PERCEPTIONS REGARDING THE OCCUPATIONAL RISKS IN VACCINATION ROOMS}

\begin{abstract}
This descriptive study with a qualitative approach aimed to identify the occupational risks in vaccinations. A total of 10 nursing technicians participated in the research; these worked in five vaccination rooms in a municipality in the North-west of the state of Rio Grande do Sul. The data were collected through semistructured interviews and simple observation, and were analyzed using thematic analysis in the period March - May 2012. It was observed that the vaccination rooms present innumerable occupational risks - and that many workers do not perceive these. There was a work surface with a basin for handwashing, but these were at a very low height in the five rooms observed, in addition to there being inadequate lighting in all rooms. The vaccinators understand occupational risks as relating only to work accidents. The attention of the municipal service for the promotion of worker's health could add value to the quality in these subjects' work.
\end{abstract}

DESCRIPTORS: Vaccines; Occupational risks; Health professionals.

\section{PERCEPCIÓN DE LOS TÉCNICOS DE ENFERMERÍA ACERCA DE LOS RIESGOS OCUPACIONALES EN SALAS DE VACUNAS}

RESUMEN: Estudio descriptivo, de abordaje cualitativo, cuyo propósito fue identificar los riegos ocupacionales en salas de vacunas. Participaron de la investigación 10 técnicos de enfermería que actúan en cinco salas de vacuna de un municipio del noroeste de Rio Grande do Sul. Los datos fueron obtenidos por medio de una entrevista semiestructurada y de observación simple, y analizados por medio del análisis temático en el periodo de marzo a mayo de 2012. Se observó que las salas de vacunas presentan muchos riegos ocupacionales y que muchos trabajadores no los perciben, pues había local para lavar las manos, pero este presentaba una altura muy baja en las cinco salas observadas, además de la iluminación deficiente en todas las salas. Las personas que aplican las vacunas entienden que los riegos ocupacionales están relacionados solamente a los accidentes de trabajo. La atención del servicio municipal de promoción de la salud del trabajador puede agregar valor a la cualidad en el trabajo de estes sujetos. DESCRIPTORES: Vacunas; Riegos ocupacionales; Profesionales de la salud. 


\section{INTRODUÇÃO}

A enfermagem, dentre os trabalhadores da área da saúde, destaca-se pela exposição a inúmeros riscos ocupacionais, pois trabalham junto a fluidos, sangue, e produtos químicos advindos da manipulação de desinfetantes, esterilizantes e medicamentos, sob condições nem sempre de conforto térmico e acústico, posturas inadequadas, ritmos fatigantes de trabalho, facilitando os acidentes de trabalho, entre outros agravos ${ }^{(1-2)}$. Os riscos ocupacionais originam-se das atividades insalubres e perigosas, podendo provocar danos à saúde do trabalhador exposto aos agentes causadores de doenças ${ }^{(3)}$.

Para reduzir o número de acidentes e os riscos ocupacionais, é necessária a criação de medidas de proteção no ambiente de trabalho. Estando o trabalhador satisfeito nas suas necessidades, nas dimensões físicas, psíquicas e sociais, incorre em menos oportunidades de desenvolverem atos inseguros e, consequentemente exposição a riscos.

O ambiente de trabalho, além de lhe trazer satisfação, deve prover segurança e a Norma Regulamentadora (NR) 32 é uma legislação que trata da segurança e saúde no trabalho em estabelecimentos de assistência à saúde, fundamental para garantir aos profissionais dessa área melhorias no ambiente de trabalho ${ }^{(4)}$, com menor exposição a riscos.

Os riscos ocupacionais estão divididos em 5 grupos de acordo com a Organização Pan-Americana de Saúde, sendo eles: físico, químico, biológico, ergonômicos e psicossocial, mecânico e de acidentes ${ }^{(5)}$. Estudos que buscam a identificação destes riscos são relevantes na medida em que conferem ao trabalhador protagonismo na gestão destes riscos, para coletivamente, buscar alternativas que intentam em evitar agravos á saúde do trabalhador, e consequentemente, afastamentos e absenteísmo.

Nessa conjuntura é pertinente contextualizar a dinâmica de trabalho dos técnicos de enfermagem que atuam em salas de vacinas, objeto deste estudo. O Programa Nacional de Imunizações (PNI) é um programa instituído com o objetivo de organizar as ações de vacinação e contribuir para a erradicação de várias doenças. Compete ao PNI acompanhar a realização das vacinas no território nacional, bem como coordenar a utilização correta das vacinas. O principal objetivo da vacinação é reduzir a morbidade e a mortalidade por doenças que podem ser prevenidas pela imunização ${ }^{(6)}$.

Nas salas de vacinas estão presentes grande número de microorganismos resistentes, como fungos, bactérias, vírus, entre outros. Por se tratar de um local onde serão administrados imunobiológicos. O local deve ser um ambiente limpo, as paredes e pisos devem ser laváveis, e deve dispor de um lavabo para limpeza das mãos. O ambiente deve ser bem ventilado e com boa luminosidade, evitando o desgaste do profissional que ali atua(6). Além disso, devem estar disponíveis materiais para assepsia e Equipamentos de Proteção Individual. Todo esse material deve dispor de local adequado para descarte, sendo de utilidade única para cada vacina.

Em relação aos de recursos humanos, para compor uma sala de vacina é necessário no mínimo dois funcionários em cada turno, um para realizar o registro da vacinação, e outro profissional para administrar a vacina. No caso de vacinação externa, que necessita locomoção da equipe de saúde, é necessário um número maior de profissionais, atendendo as necessidades e a demanda da população(6).

Os profissionais que atuam em salas de vacinas devem estar atentos em aspectos importantes, como via e local de administração da vacina, validade, conservação, bem como, a idade recomendada para cada vacina, intervalo entre uma dose e outra, e a composição da vacina. É indispensável a lavagem das mãos, antes e após realizar qualquer procedimento com as vacinas, poisé um dos métodos mais importantes na prevenção de infecções ${ }^{(6)}$.

Diante do exposto, e pela complexidade que representam os imunobiológicos e a sala de vacinas à saúde do trabalhador na dinâmica do cotidiano laboral em ambientes como este, o estudo justifica-se e tem como objetivo identificar os riscos ocupacionais em salas de vacinas, na perspectiva do trabalhador desse ambiente.

\section{MÉTODO}

Pesquisa de abordagem qualitativa e descritiva. Os dados foram coletados entre fevereiro a março de 2012. Participaram da pesquisa 10 técnicos de enfermagem que atuam em cinco salas de vacina de um município situado no noroeste do estado do Rio Grande do Sul. Definiu-se a amostra 
de 10 participantes na pesquisa embasada no que preconizam autores de que nas pesquisas qualitativas a saturação dos dados começa a evidenciar-se por volta da $10^{a}$ entrevista ${ }^{(7-8)}$. Foram visitadas todas as salas de vacinas do município e convidados todos técnicos de enfermagem. Os critérios de inclusão para a pesquisa foram: ser técnico de enfermagem, trabalhar em sala de vacina e aceitar participar do estudo.

Os dados foram coletados por meio de entrevista semiestruturada ${ }^{(7)}$ com os trabalhadores, nas respectivas salas de vacinas. Além disso, o pesquisador utilizou-se da observação simples para complementar os dados. Assim, nos dias em que foram realizadas as entrevistas, o entrevistador permaneceu no local durante o turno a fim de observar a presença de riscos ocupacionais no ambiente, perfazendo cinco períodos de 1 a 2 horas.

Em relação às observações, foram realizadas anotações em um diário de campo, sobre os ambientes das salas de vacinas que envolveram aspectos da área física, mobiliários, iluminação, ventilação, ruídos, preparo das vacinas, essas ajudaram a compreender melhor as informações obtidas pelas entrevistas. A análise dos dados foi feita mediante análise do conteúdo das falas dos sujeitos ${ }^{(7)}$. A pré-análise consistiu na leitura exaustiva das falas, que foi seguida pela organização do material. A partir da exploração desse material codificou-se e categorizou-se os resultados e, mediante a interpretação, discutiu-se com a literatura científica pertinente. Da análise dos dados surgiram duas categorias: Percepção dos técnicos de enfermagem em relação aos riscos ocupacionais e Riscos ocupacionais nas salas de vacinas.

Foram respeitadas as diretrizes e normas regulamentadoras de pesquisa com seres humanos, do Conselho Nacional de Saúde ${ }^{(9)}$. Para preservar o sigilo das entrevistadas foram usados nomes de flores. Os dados foram coletados após a aprovação pelo Comitê de Ética da Universidade Regional Integrada do Alto Uruguai e das Missões, Campus de Santo Ângelo, sob o protocolo número 0121-4/PPH/11.

\section{RESULTADOS}

Participaram do estudo 10 técnicas de enfermagem, todas do sexo feminino, com idades entre 32 a 54 anos. A maioria é casada e metade delas possuem dois empregos. Os dados empíricos foram organizados e submeti $\neg$ dos à leitura e re-leitura visando à obtenção dos núcleos de sentido, extraindo-se duas categorias temáticas: Percepção dos técnicos de enfermagem em relação aos riscos ocupacionais e Riscos ocupacionais nas salas de vacinas.

Em relação a categoria Percepção dos técnicos de enfermagem em relação aos riscos ocupacionais foi possível perceber que nem todos se apoderaram desse conhecimento de modo amplo, sendo observado nas seguintes falas:

Tudo o que acontece com movimentos repetitivos e também postural. (Margarida)

São sequelas causadas por excesso de esforço repetitivos [....]. (Bromélia)

Quanto ao entendimento quanto ao risco ocupacional e local destes riscos as falas foram:

Muito trabalho, falta material adequado, espaço físico. (Rosa)

É o risco que a sua função apresenta, biológicos. (Violeta)

A sala de vacinas é um ambiente de prevenção e como tal oferece menos risco ocupacionais que os demais, no ambiente de saúde [...]. Existem alguns como, por exemplo, ferir-se na abertura dos frascos e picar-se com agulhas. (Azaléia)

Para a categoria Riscos ocupacionais nas salas de vacinas ressaltamos as seguintes falas:

Dores nas costas e pernas, às vezes. (Hortência)

Dores com frequência nas costas, pernas e braços. (Margarida)

Sinto dores pernas e costas com frequência. (Bromélia)

Apesar das dores nas costas, pernas e braços evidenciadas pelas técnicas, nenhuma delas 
relacionou esses fatores com a altura e conservação dos mobiliários, mas atribuíram ao fato de aplicar as vacinas:

O movimento de puxar as vacinas e administrar dá dor no ombro e braço. (Margarida)

Lesão por esforço repetitivo. (Genciana)

Foi questionado se alguma vacinadora já havia cometido algum tipo de erro e três delas relataram:

Sim, aplicação de outra vacina. (Tulipa)

Sim, diluição, aplicação. (Bromélia)

Não, mas já presenciei administração de imunobiológicos errada. (Íris)

As participantes foram questionadas a que fatores se atribuem os erros nas salas de vacinas, as respostam foram:

Devido ao excesso de trabalho. (Bromélia)

Estresse, atenção. (Tulipa)

Acúmulo de trabalho, pouco profissional. (Rosa)

Na maioria das vezes quando as pessoas cometem erro, é acúmulo de trabalho, pra pouco trabalhador. (Begônia)

O ambiente de trabalho nas cinco salas de vacina, foi possível perceber que em todas elas havia balcão com pia para lavar as mãos e mesa para preparar os imunobiológicos. Porém as pias estavam em uma altura baixa, não adequada nas cinco salas e em três delas a mesa para preparo das vacinas era constituída de material impróprio para assepsia; além de altura inadequada e estado de má conservação. Em duas salas de vacinas não havia mesa para o manejo delas, desta forma, as vacinas eram preparadas nas pias.

Além disso, foi possível observar também que, das cinco salas de vacinas, apenas duas apresentavam mobiliário adequado para a triagem dos pacientes antes da realização delas, com altura adequada e em estado de conservação aceitável. Essa percepção ainda foi valorizada após terem sido questionadas se haviam algum tipo de dor e com que frequência.

Durante o período em que as salas foram observadas, foi possível perceber que a iluminação estava fraca em todas elas, e, além disso, em uma delas a sala tinha o piso de cor preta, o que desfavorecia ainda mais a iluminação. Em relação à ventilação, todos os cômodos de vacinação são equipados com ares condicionados, equipamentos esses que ajudam a manterem as vacinas dentro da temperatura recomendada pelo Ministério da Saúde.

Observou-se, que nem sempre esses equipamentos estão ligados, e em uma das salas não há janelas para ventilação. Além disso, esses aparelhos quando ligados produzem ruídos, dificultando a acuidade auditiva.

\section{DISCUSSÃO}

\section{Percepção dos técnicos de enfermagem em relação aos riscos ocupacionais}

A equipe de enfermagem está exposta a inúmeros riscos ocupacionais quando desenvolve suas atividades. Dessa forma é importante que todos esses trabalhadores entendam o que são riscos ocupacionais para que possam estar atentos a eles a fim de evitar ou minimizar acidentes de trabalho ou doenças ocupacionais.

Os resultados demonstram que ocorre o desconhecimento por parte destes profissionais de enfermagem em relação ao processo de trabalho e sua relação com os riscos ocupacionais, provocado muitas vezes pela dificuldade desses profissionais em compreender o trabalho como um possível causador de doenças e de acidentes de trabalho, o que pode ser atribuído à deficiência de conhecimento sobre o que são riscos ocupacionais. Isso ficou demonstrado no momento em que as entrevistadas atribuíram os riscos ocupacionais apenas ao risco ergonômico.

Entende-se por riscos ocupacionais aquelas situações existentes no trabalho, capazes de provocar um desequilíbrio físico, mental ou social dos trabalhadores e não somente aquelas condições que acarretam doenças ou 
acidentes do trabalho. Ou seja, a natureza do exercício de cada função tem a probabilidade de ocasionar lesão física, psíquica ou patrimonial, sendo necessário que o trabalhador conheça os riscos a que está exposto(10).

Quanto ao significado do risco ocupacional, percebe-se têm-se melhor entendimento sobre risco ocupacional, pois o relacionam a sobrecarga, agente psicossocial, espaço físico, agente ergonômico, a agentes intrínsecos ao contato com seres humanos doentes, os microrganismos. Uma das entrevistadas, por sua vez, entende que na sala de vacina existem menos riscos ocupacionais.

Quanto ao risco biológico citado pela Violeta e pela Azaléia, existe uma potencial possibilidade de acidentes com perfurocortantes nesse ambiente, considerando que o principal instrumento de trabalho são as seringas, agulhas e ampolas utilizadas no preparo e aplicação dos imunobiológicos.

A equipe de enfermagem representa o maior número de trabalhadores na área da saúde e por isso tem elevado o número de trabalhadores desempenhando algum tipo de procedimentos sujeitos a exposição ocupacional ${ }^{(11)}$. Sabe-se que acidentes com material perfurocortantes ainda os expõe muito, apesar das precauções padrão recomendarem o uso de EPI e o não reencape de agulhas. Um estudo demonstrou que no momento da ocorrência da exposiç̧ão ao material biológico, $60,8 \%$ dos profissionais relataram estar utilizando EPI durante o procedimento contra 28,5\% não faziam o uso do mesmo ${ }^{(12)}$, que comprova a adesão incompleta dos trabalhadores a esses equipamentos e a consequente vulnerabilidade à exposição.

Foi demonstrado em uma pesquisa realizada no Rio de Janeiro, que a maioria dos profissionais da enfermagem consideram a profissão arriscada, mas $49 \%$ do total dos acidentados entrevistados consideram que em seu trabalho de enfermagem os riscos de acidentes com materiais perfurocortantes são baixos ou quase nulos. Faltam a esses sujeitos esclarecimentos sobre biossegurança, condições inadequadas e sobrecarga de trabalho sobre os riscos de contraírem doenças e de se acidentar a qualquer momento ${ }^{(13)}$, dados preocupantes quando se refere ao autocuidado.

\section{Riscos ocupacionais nas salas de vacinas}

As dores mencionadas no presente estudo, foi relatada por quase todas as entrevistadas, podem estar relacionadas com a postura inadequada em que as trabalhadoras apresentam ao receber os pacientes para triagem, ao lavar as mãos e ao preparar as vacinas para serem aplicadas. Poderiam ser evitadas ou minimizadas elevando a altura desses mobiliários.

A NR 17 estabelece parâmetros que permitam a adaptação das condições de trabalho às condições psicofisiológicas dos trabalhadores, de maneira que possam proporcionar um máximo de conforto, segurança e desempenho eficiente, ou seja, o trabalho desempenhado em pé ou sentado, deve ter bancadas, mesas ou escrivaninhas capazes de proporcionar ao trabalhador condições de boa postura, visualização e operação. Essa mesma norma regulamentadora associa os riscos ergonômicos à sobrecarga e sobre-esforços, à postura irregular dos profissionais de enfermagem, com flexões frequentes da coluna e mobilização de pacientes e, além disso, projeto inadequado do posto de trabalho ${ }^{(14)}$.

Além disso, é necessária muita atenção no preparo dos imunobiológicos, pois a maioria dos frascos que contém as vacinas são semelhantes, podendo ocasionar erro na hora do preparo e na via de aplicação, pois as vacinas têm vias diferentes de aplicação. Nesse sentido, a iluminação e altura da mesa de preparo são importantes não somente para evitar riscos ocupacionais, mas também para evitar erros na aplicação. As salas de vacinas exigem muita atenção e concentração, pois qualquer tipo de erro pode resultar em danos a saúde da pessoa que está sendo vacinada.

A sobrecarga de trabalho associada ao número reduzido de trabalhadores, à complexidade das tarefas, à pressão do tempo e o acúmulo de dois empregos podem produzir em algumas vacinadoras fadiga e tensão, vindo a constituir-se em riscos psicossociais responsáveis por situações de estresse relacionado com o trabalho. Riscos psicossociais no trabalho podem ser todos os aspectos e vivências do processo de trabalho e que tem potencial para desencadear dano físico ou psicológico ${ }^{(15)}$.

Como consequências da sobrecarga/ excesso de trabalho, uma revisão da literatura demonstrou frequentes acidentes com materiais perfurocortantes ou com fluídos e secreções 
corporais; problemas de saúde, como contusões, hipertensão arterial, alergias, epigastralgias, problemas musculoesqueléticos, adoecimento/ sofrimento mental, entre outros. Apontaram também, que são causas de afastamento do trabalho por parte da equipe de enfermagem, embora grande parte dos trabalhadores não percebam os riscos ocupacionais a que estão expostos, tal como no nosso estudo ${ }^{(16)}$.

As técnicas de enfermagem relacionaram os erros em suas atividades somente com o risco psicossocial. Nenhuma das trabalhadoras citou esses riscos como possíveis causadores de erros na aplicação dos imunobiológicos. Ainda é escassa a construção do conhecimento acerca dos riscos físicos e muitos trabalhadores não identificam seus agentes como causadores de adoecimento $^{(17)}$.

\section{CONSIDERAÇÕES FINAIS}

Este estudo possibilitou conhecer a percepção dos profissionais de enfermagem quanto aos riscos ocupacionais em salas de vacinas, bem como identificar os riscos existentes nesse ambiente. A partir da análise dos dados, foi possível perceber que a maioria das vacinadoras do setor estudado desconhecem os riscos ocupacionais ali existentes, visto que a maioria das entrevistadas citou apenas o risco ergonômico e o biológico.

É importante que o Serviço de Saúde do Trabalhador do município acompanhe as condições de saúde e as do ambiente de trabalho, implementando medidas de promoção e prevenção da saúde dos trabalhadores. Ao gestor da saúde cabe o entendimento sobre tais riscos ocupacionais, sua gravidade e a implantação das medidas necessárias para seu controle, para que dessa maneira possa incentivar e apoiar a busca pela melhoria das condições de trabalho.

Sugerem-se estudos que estudem os riscos ocupacionais nas em unidades básicas de saúde, considerando a lacuna identificada nestas áreas e cenários.

\section{REFERÊNCIAS}

1. Espindola MCG, Fontana RT. Riscos ocupacionais e mecanismos de autocuidado do trabalhador de um centro de material e esterilização. Rev. Gaúcha Enferm.
2012;33(1):116-23.

2. Gallas SR, Fontana RT. Biossegurança e a enfermagem nos cuidados clínicos: contribuiçõos para a saúde do trabalhador. Rev. bras. enferm. 2010;63(5):786-92.

3. Castro MR, Farias SNP. A produção científica sobre os riscos ocupacionais a que estão expostos os trabalhadores de enfermagem. Esc. Anna Nery. 2008;12(2): 364-9.

4. Robazzi MLCC, Marziale MHP. A norma regulamentadora 32 e suas implicações sobre os trabalhadores de enfermagem. Rev. Latino-Am. Enfermagem. 2004;12(5):834-6.

5. Ministério da Saúde (BR). Organização Pan-Americana da Saúde. Doenças relacionadas ao trabalho: manual de procedimentos para os serviços de saúde. Brasília, 2001.

6. Ministério da Saúde (BR). Fundação Nacional de Saúde. Manual de Procedimentos para Vacinação. Brasília, 2001.

7. Minayo MCS. O desafio do conhecimento: pesquisa qualitativa em saúde. 10ª ed. SãoPaulo(SP): Hucitec; 2007.

8. Lobiondo WG, Haber J. Pesquisa em enfermagem: métodos, avaliação crítica e utilização. $\quad 4^{\mathrm{a}} \mathrm{ed}$. Rio de Janeiro (RJ): Guanabara Koogan; 2001.

9. Ministério da Saúde (BR). Conselho Nacional de Saúde. Diretrizes e normas regulamentadoras da pesquisa envolvendo seres humanos: Resolução n. 196/96. Brasília, 1996.

10. Bessa MEP, Almeida MI, Araújo MFM, Silva MJ. Riscos ocupacionais do enfermeiro atuante na Estratégia Saúde da Família. Rev. enferm. UERJ. 2010;18(4):644-9.

11. Cavalcante CAA, Enders BC, Menezes RMP, Medeiros SM. Riscos ocupacionais do trabalho em enfermagem: uma análise contextual. Cienc. cuid. saude. 2006;5(1):88-97.

12. Gomes AC, Agy LL, Malaguti SE, Canini SRMS, Cruz EDA, Gir E. Acidentes ocupacionais com material biológico e equipe de enfermagem de um hospitalescola. Rev. enferm. UERJ. 2009;17(2):220-3.

13. Alves SSM, Passos JP, Tocantins FR. Acidentes com perfurocortantes em trabalhadores de enfermagem: uma questão de biossegurança. Rev. enferm. UERJ. 2009;17(3):373-7.

14. Ministério do Trabalho e Emprego (BR). Manual de aplicação da Norma Regulamentadora $n^{\circ} 17.2^{a}$ ed. Brasília, 2002.

15. Cox T, Griffiths AJ. The assessment of psychological hazards at work. In Shabracq MJ., Winnubst JA, 
Cooper CL. Handbook of work and health psychology. Chichester: Wiley\& Sons; 1995.

16. Silva MKD, Zeitoune RCG. Riscos ocupacionais em um setor de hemodiálise na perspectiva dos trabalhadores da equipe de enfermagem. Esc. Anna Nery. 2009;13(2):279- 86.

17. Castro MR, Farias SNP. A produção científica sobre riscos ocupacionais na enfermagem a que estão expostos os trabalhadores de enfermagem. Esc. Anna Nery. 2008;12(2):364-9. 